\title{
The Effect of Practicing Mental Calculation Strategies on Teacher Candidates' Numeracy Proficiency
}

\author{
Masooma Ali Al Mutawah \\ Bahrain Teachers College (BTC), University of Bahrain, PO box 32038, Kingdom of Bahrain \\ E-mail: malmutawah@uob.edu.bh
}

Received: 23-11- 2015

Accepted: 04-04-2016

Published: 30-04-2016

doi:10.7575/aiac.ijels.v.4n.2p.1

URL: http://dx.doi.org/10.7575/aiac.ijels.v.4n.2p.1

\begin{abstract}
This study was conducted on year 4 students enrolled in the Bachelor of Education program for Cycle one teacher candidates. The effect of practicing mental calculation strategies in improving students' numeracy proficiency was put under some tests to measure its effect in a scientific way. A Pre-quiz was conducted before with no prior practice done in order to check the strategies the students were using in performing calculations. After four weeks practice and implementation which focused mainly on addition and subtraction questions, as a result a post quiz was written by the students. The improvement results were recorded and analyzed. After four weeks of practicing multiplication and division questions, another post quiz was written by the students as a result of that. Once again, the improvement results also were recorded and analyzed. Furthermore, interviews and observations also were used to record changes in the students' perspectives about using the mental strategies and their feelings toward their numeracy level. The results of the study showed that practicing the mental strategies had a significant impact on the students' numeracy proficiency and their perspective toward their mental strategies. The study also showed that more practice had a significant impact on the students' confidence as well as their ability to perform different mental strategies in their daily life.
\end{abstract}

Keywords: Calculation strategies, Numeracy proficiency

\section{Introduction}

Keeping up with the recent pedagogy in teaching and learning numeracy is important for mathematics lecturers in higher education. Especially for those who are specializing in the field of teacher training. Bahrain primary math curriculum developer(s) and specialists have been putting a lot of emphasis in mental calculation strategies recently, which has resulted in putting extra pressure on lecturers to continuously improve their practices which may reflect on their students' practices as future math teachers.

Today, teaching students 1or 2 strategies to calculate numbers is not enough with all the diverse learners we have in our classes. Research findings point out the importance of using mental calculation strategies since the traditional methods are not effective enough to improve students' numeracy proficiency (Thompson, 2009). So 'What are the best practices to teach mental strategies?' and 'How to improve students' numeracy proficiency?'

This research aims to improve the numeracy proficiency of teacher candidates by giving them the opportunity to practice the mental strategies for some time to check if the practice has any positive effects on their implementation strategies learned. Some researchers mentioned that trainee teachers need to be familiar with mental calculation strategies not necessarily to convince them to use them but at least to enable them to recognize them when they are used by their pupils (Thompson, 2009). Giving students theories and literatures to persuade them about the effectiveness of specific strategies or to encourage them to use them/it is not enough. Jones (2004) mentioned that the quality of numeracy teaching is effective when teachers use various learning practical tasks and provide regular mental work sessions. Two of the seven factors which lead to successful learning are 'learning by doing' and 'making sense of things' (Race, 2010). So, this study seeks to expose students to these two successful learning factors, experiment these strategies, help the students realize the rationale behind them, and finally test the effect of these strategies on students' learning.

A large body of related literature talks about the importance of using mental calculation strategies in improving students' proficiency with regards to calculation performance. The Ministry of Education of Bahrain is trying its best to change students' current calculation methods to be more mental. However, still the majority of students and teachers cannot see the importance of these methods. Furthermore, teacher candidates do not consider these mental strategies as a good transform. They prefer the vertical traditional method which they think is easier and does the required calculation accurately.

It is important that teacher candidates change the way they look at these mental strategies by having them practice them, and then test the changes that appear in their numeracy proficiency. The main purpose of this study is to answer the 
following question: How could practicing mental calculation strategies improve teacher candidates' numeracy proficiency?

\section{Literature Review}

Many researchers studied the reform in numeracy in countries all over the world (Brown et al 2003; Thompson 2000). Also many investigated the effect of using mental strategies on students' numeracy (Craig 2010; Murphy 2004). Mathematics researchers recommend the use of mental strategies because they enable students to understand the structure of numbers, learn how numbers work and develop cognitive and metacognitive thinking (Heirdsfield and Lamb, 2005, p.419). John Threlfall (2002) mentioned since calculating is an important learning outcome in mathematics education, it is essential to be flexible in mental calculation by using efficient methods'.

This study will investigate the effect of practicing mental strategies on students' numeracy proficiency. Maclellan (2001) mentioned that acquiring the best pedagogical practices to increase the emphasis in mental strategies comes from defining it properly. Hence, this study will define the mental strategies as 'The application of known or quickly calculated number facts in combination with specific properties of the number system to find the solution of a calculation whose answer is not known' (Thomson 1999, p. 2), and the numeracy proficiency as 'selecting the most appropriate strategy to be used according to the specific numbers involved in a question'.

Doabler et al. (2012) mentioned that core math instruction has a unique role in helping students to become proficient in mathematics. That is why it is important to move from concentrating on the conceptual-knowledge to the proceduralknowledge. Students who lack procedural fluency will rely on less sophisticated strategies, and will only be able to recall answers to basic number combinations.

Maclellan (2001) mentioned that we can learn a lot about students' knowledge and skill from the strategy they choose to partition a number, because each way of partitioning can tell us something different about students' ability in working with number bonds, place value, operate with powers-of-10. Determining the mental strategy is important to know how to help students to be more proficient. Biggs and Tang (2011, p.22) stated that 'all the forms of constructivism lead to one theory which emphasizes that learners develop their own schemata based on the knowledge they constructed by their own activities'. According to Piaget (as cited in Rivera, 1996) students who achieve knowledge through free investigation will have acquired a methodology that serves them for the rest of their life.

Also many studies investigated the importance of hearing students' views about their numeracy learning (Loveridge and Taylor, 2005; Heirdsfield and Lamb, 2005). This study will also try to investigate students' perspectives about their numeracy learning by conducting interviews and see how students feel about the mental strategies and how their perspectives can affect their numeracy learning.

\section{Method}

This was an action research study. Mixed methods were followed in collecting and analyzing the data.

\subsection{Sample}

The study sample was 47 students enrolled in TC1MAT412 which is a Year 4 course from Cycle1, B.Ed program. Students voluntarily participated in the study. They were informed that research findings will not affect their grades, and their data will remain anonymous.

\subsection{Data collection}

Three data collection tools were used, one quantitative (quizzes) and two qualitative (Interviews and observations). Three quizzes were used at three stages of the study to check students' numeracy proficiency. The strategies students used to solve the questions were analyzed and recorded. All the quizzes were of the same difficulty level and had exact instructions. Each quiz was consisting of 5 addition, 5 subtraction, 5 multiplication, and 5 division questions.

Open Interview questions were used at two stages of the study to check students' perspective about practicing and using different mental strategies.

Mertler (2012) argued that observations enable the researcher to gather actual behaviors from the participant. In this study, students were observed while they were practicing throughout the whole study period, changes appearing in their behaviors during their practice were recorded.

\subsection{Procedure}

The treatment was provided twice a week, for 9 weeks and 20 minutes per lesson for practicing and other lessons for collecting the data (Table 1). 


\begin{tabular}{|c|c|c|c|c|}
\hline Phase 1 & \multicolumn{4}{|c|}{ Pre-cycle } \\
\hline $\begin{array}{l}\text { Practicing sessions } \\
\text { (20 minutes each) }\end{array}$ & \multicolumn{4}{|c|}{ No practice } \\
\hline Data collection method & \multicolumn{4}{|c|}{ Pre-Quiz } \\
\hline Data collection sessions & \multirow{2}{*}{\multicolumn{4}{|c|}{$\begin{array}{l}\text { Lesson } 1 \\
\text { Cycle } 1\end{array}$}} \\
\hline Phase 2 & & & & \\
\hline $\begin{array}{l}\text { Practicing sessions } \\
\text { (20 minutes each) }\end{array}$ & Lesson $2 \quad$ Lesson 3 & Lesson 5 & Lesson 6 & Lesson 7 \\
\hline Data collection method & \multirow{2}{*}{$\begin{array}{l}\text { Cycle } 1 \text { Quiz } \\
\text { Lesson } 9\end{array}$} & Interviews & \multirow{2}{*}{\multicolumn{2}{|c|}{$\begin{array}{c}\text { Observations } \\
\text { Lessons 2-8 }\end{array}$}} \\
\hline Data collection sessions & & Lesson 10 & & \\
\hline Phase 3 & \multicolumn{4}{|c|}{ Cycle 2} \\
\hline $\begin{array}{l}\text { Practicing sessions } \\
\text { (20 minutes each) }\end{array}$ & $\begin{array}{lll}\text { Lesson } 11 & \text { Lesson } 12 & \text { Lesson } 13\end{array}$ & Lesson 14 & Lesson 15 & Lesson $16 \quad$ Lesson 17 \\
\hline Data collection method & Cycle 2 Quiz & Interviews & & Observations \\
\hline Data collection sessions & Lesson 18 & Lesson 19 & & Lessons 11-17 \\
\hline
\end{tabular}

As the table shows, the study was done in three phases as the following:

3.3.1 Pre-Cycle

In the first lesson the pre-Quiz was administered, the aim was to see students' numeracy proficiency level. The quiz 20 questions were written with consideration of the best strategies they can be solved by. The strategies which the students used were organized and analyzed.

\subsubsection{Cycle 1}

The element of change at this cycle was practicing addition and subtraction mental strategies. At the end of the cycle, students wrote down a quiz to check if their proficiency was improved. Data of the test were organized and analyzed. Some of the students who showed high, moderate or low improvement were interviewed. Also students' behavior and enthusiasm was observed and noted. The study expected a significant change in students' proficiency at adding and subtracting, and I was predicting some changes in students' proficiency level in multiplying and dividing since all the operations are related to each other.

\subsubsection{Cycle 2}

The element of change at this cycle was practicing multiplying and dividing strategies, which will prove that if any change happened at cycle1 it was because of the practice not because of the content. Students continued the practice, then wrote another quiz to check if their proficiency improved. The study predicted a significant improvement over the four operations' strategies. Data were organized and analyzed. Some of the students who showed high, moderate or low improvement were interviewed. Also students' behavior was observed and noted.

\section{Results and Discussion}

The results indicated that all the academic levels of the sample group preferred regrouping, while sequencing and partitioning obtained the lowest percentages in usage (Figures $1 \& 2$ ).

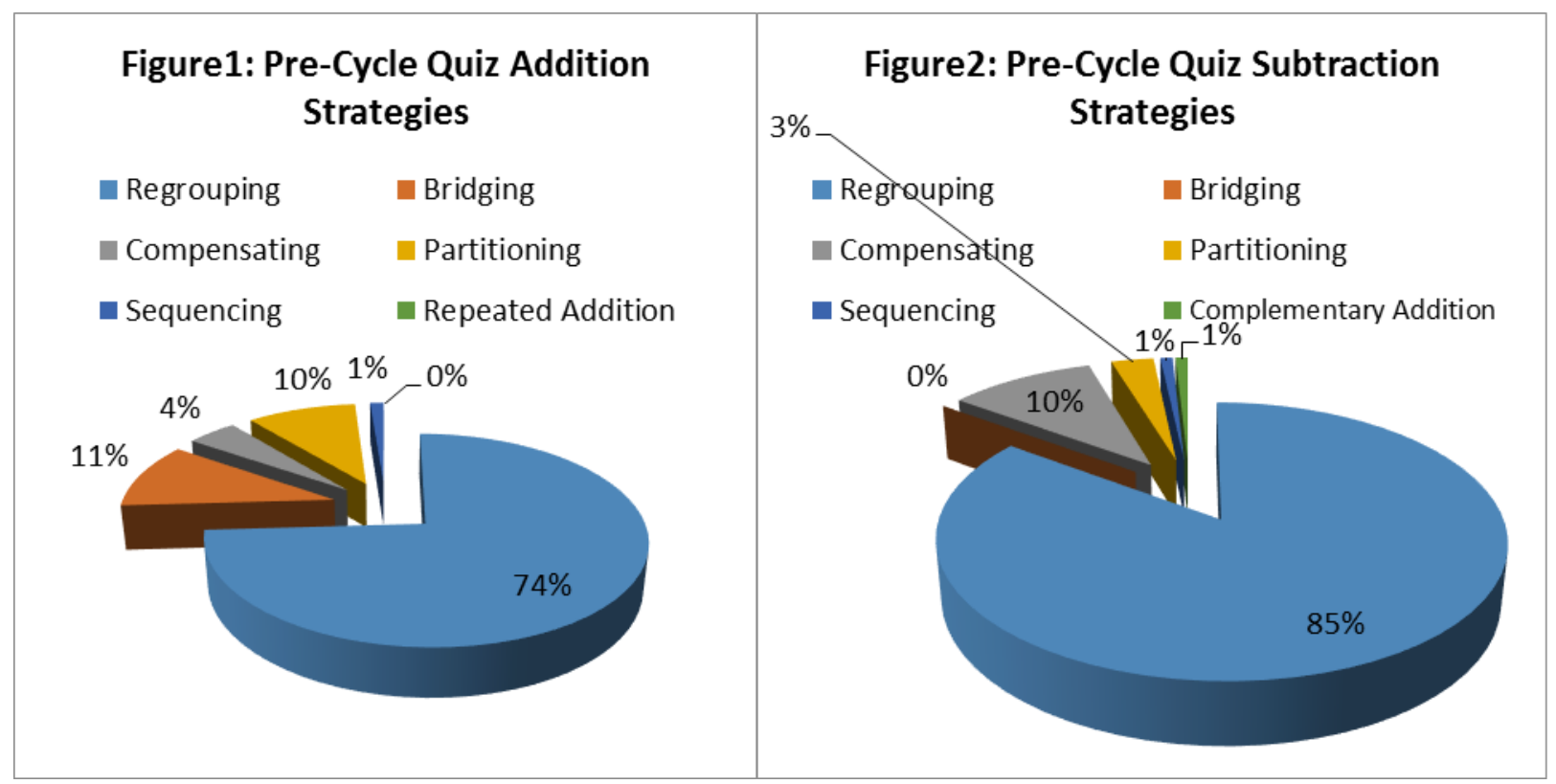


In their study, Foxman and Beishuizen (2002) found that mental strategies differed from one student to another according to their academic math level. They found that high level students preferred sequencing, low level students preferred partitioning, while the majority preferred regrouping.

The results for multiplication and division were the same as those for addition and subtraction. Decomposing and long division were used by the majority of the study sample (Figures 3\&4). Even though these two methods are not easy, as they require holding up some mental operations and using them later in the process, they were the most preferable methods by the study sample. In a study for Loveridge and Taylor (2005), they mentioned that students might prefer to use more sophisticated methods because they did not realize that they were harder, since they learned these traditional methods before the mental methods.

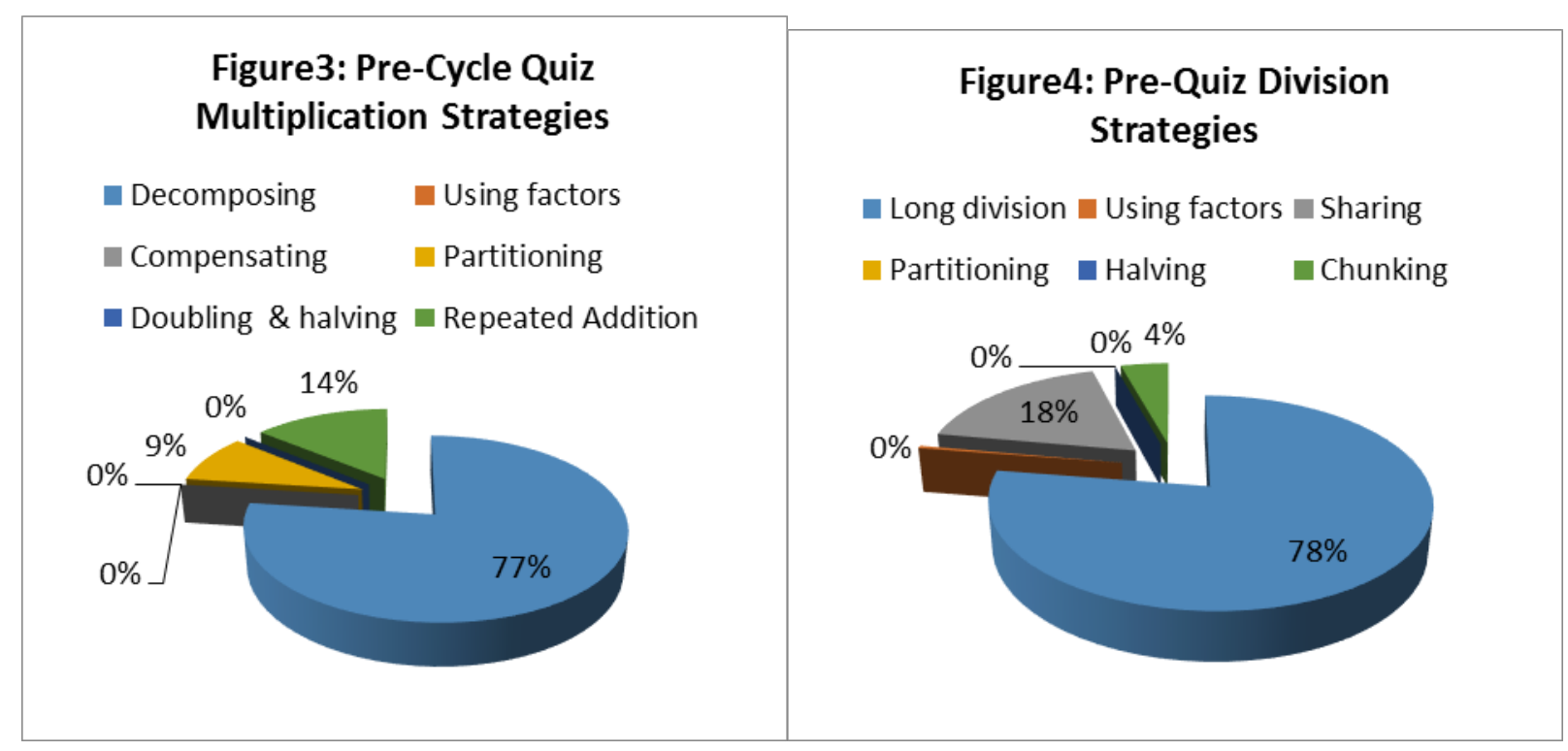

It was obvious that students preferred the traditional methods in all operations; only few students attempted using the mental strategies as illustrated in the pie-charts (Figures $3 \& 4$ ).

In the practicing sessions, students' behavior was observed. At the beginning students were less confident; many of them were not writing as observed by their instructor. Loveridge and Taylor (2005) found similar reactions in their study; they discussed that many students were afraid of trying something new because they did not want to avoid making mistakes. But, at the last lessons of Cycle1, the students were more confidant and interested. It could be because they had realized the ease of use of these strategies, as also mentioned by many of them later in the interviews during the Cycle1 quiz results (Figures 5\&6).

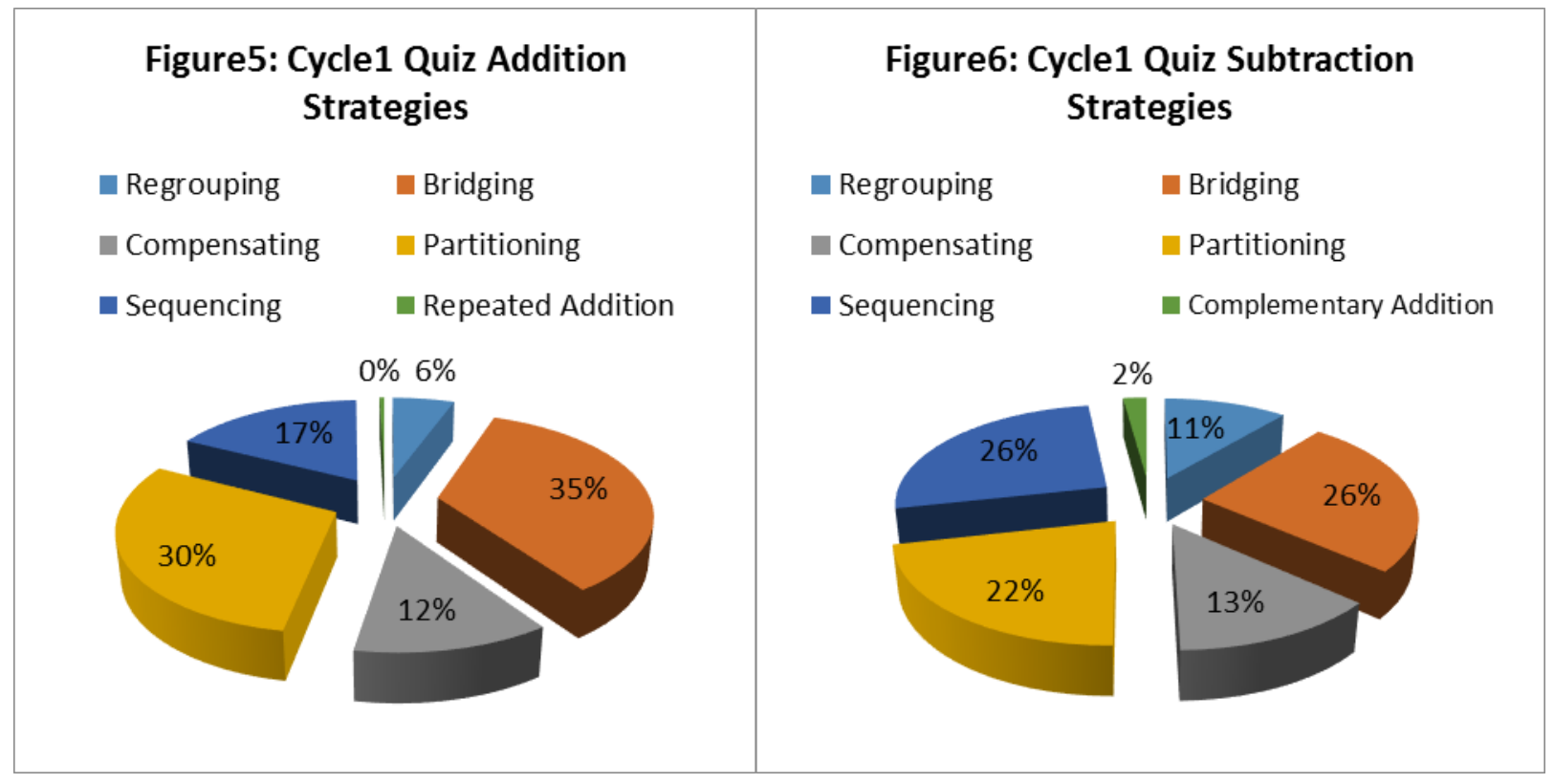

As the figures show, regrouping was the second lowest strategy used by the students whereas bridging was the most preferable. No one used repeated addition, which was expected, since it is a low level thinking strategy that can be used with small numbers only (Anghileri, 2006). Students were asked in the interviews why they did not use complementary 
addition. Many of them mentioned that it was not a difficult strategy but they did not think of addition when they were subtracting. Surprisingly, little improvement was shown in multiplication and division in this cycle (Figures 7\&8).

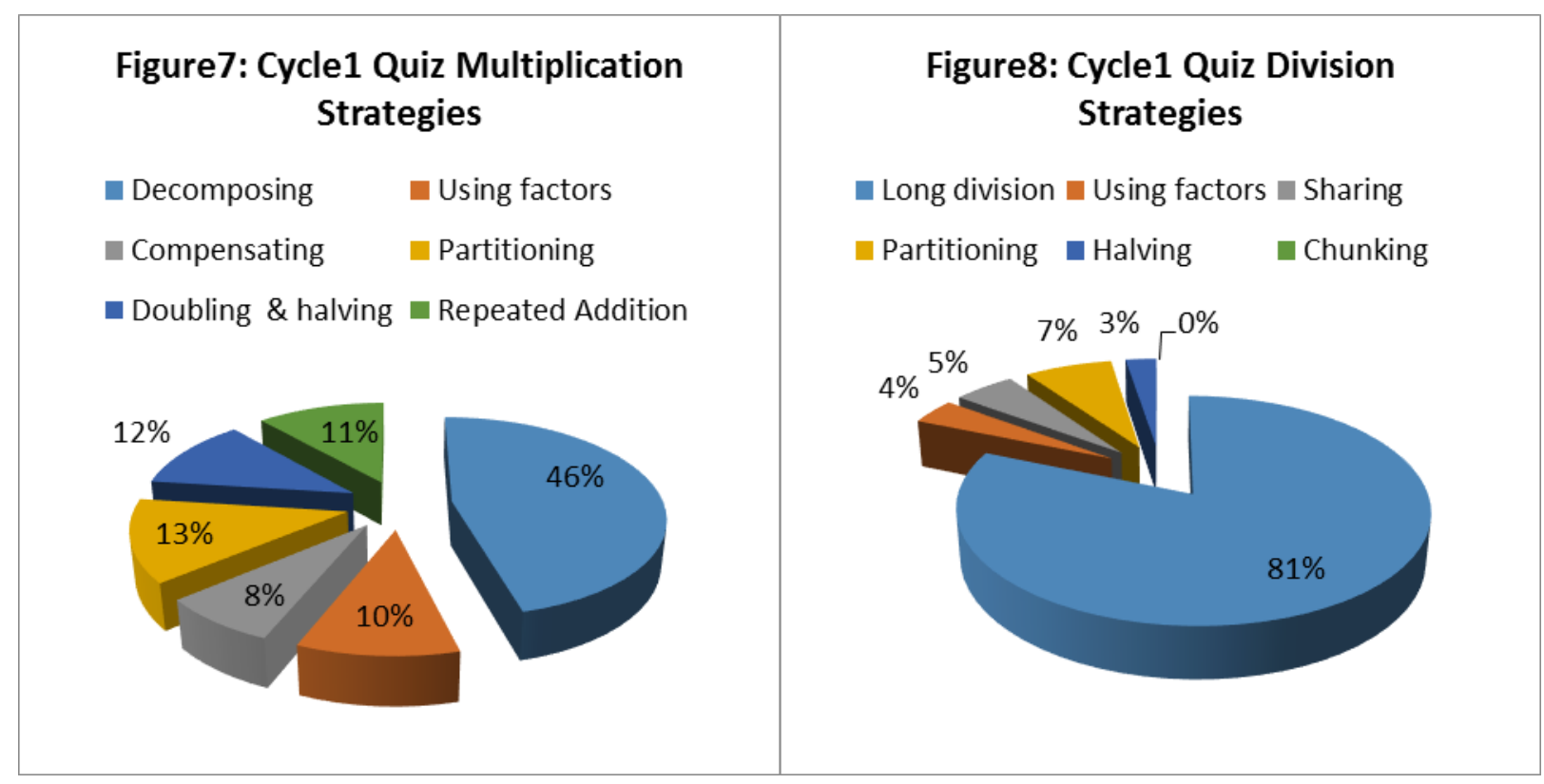

While analyzing the students' results in this cycle, many improvements were evident in their proficiency in adding and subtracting. It was obvious from their different choices of strategies that they were more aware about where to use each one (Tables 2\&3). For example, 28 students solved Question $1(38+17)$ by bridging $(38+2=40+15=55)$, which might have been the best strategy to solve it (Heirdsfield and Lamb, 2005). Also 25 students solved Question 7 (56-19) by compensating $(56-20=36+1=37)$, which might have been the best strategy to solve it (Foxman \& Beishuizen, 2002).

One of the important characteristics of the mental strategies is that they are holistic, which means they deal with the complete number rather than splitting it to ones and tens as the traditional methods do (Plunkett, 1979, as cited by Foxman and Beishuizen, 2002, p. 47). So, moving to use these methods in solving indicated that the students were starting to have the sense of the number value and becoming more numerate. Below is some feedback from the students after this cycle, which can explain these changes:

Participant 7: She used bridging, compensating, sequencing, and partitioning in adding and subtracting. She said "practicing made me believe that all these strategies are better than regrouping. I can perform faster when I am using them". About using some multiplying strategies without practicing them, she said "I saw how faster I can perform using the mental strategies in adding and subtracting, so I tried to use them in multiplying because I realized that they can be used in multiplying too!" She showed a lot of passion about using the mental strategies; she said "The way I look at calculation today is totally different; I am confidant; I am using the mental strategies in my daily life. Before the practice I thought they are difficult, but I am happy to get the opportunity to see the wonder behind them!"

Participant 5: He used only partitioning for all the adding and subtracting questions. He said, "We only spent 4 weeks to practice, so the only method I felt confident to use was partitioning. It is reasonable and easy, but I was not sure that I can use the other strategies without making mistakes." He used repeated addition for 3 questions, about that he mentioned, "After practicing the mental strategies, I really believe that regrouping the number is not efficient to improve our numeracy proficiency; that is why, I tried to multiply by repeated addition to keep the value of the number."

Participant 32: He used regrouping for almost all the adding and subtracting questions. He said, "I still think regrouping is the easiest strategy; I can perform very well with it, so, why should I change it!?"

This is similar to Quirk's (2013) results. He found that students, with "No algorithms" experience, performed the best on the mental math test, which could be because it is difficult to change what students have been used to doing for a long period.

During Cycle2, students practiced multiplying and dividing for 4 more weeks. Based on the researcher's observation, there was a considerable change in their enthusiasm. They were so excited about learning these strategies, and many of them were waiting for these sessions and asking questions to learn more about them. Cycle 2 quiz results were very promising (Figures 9\&10).

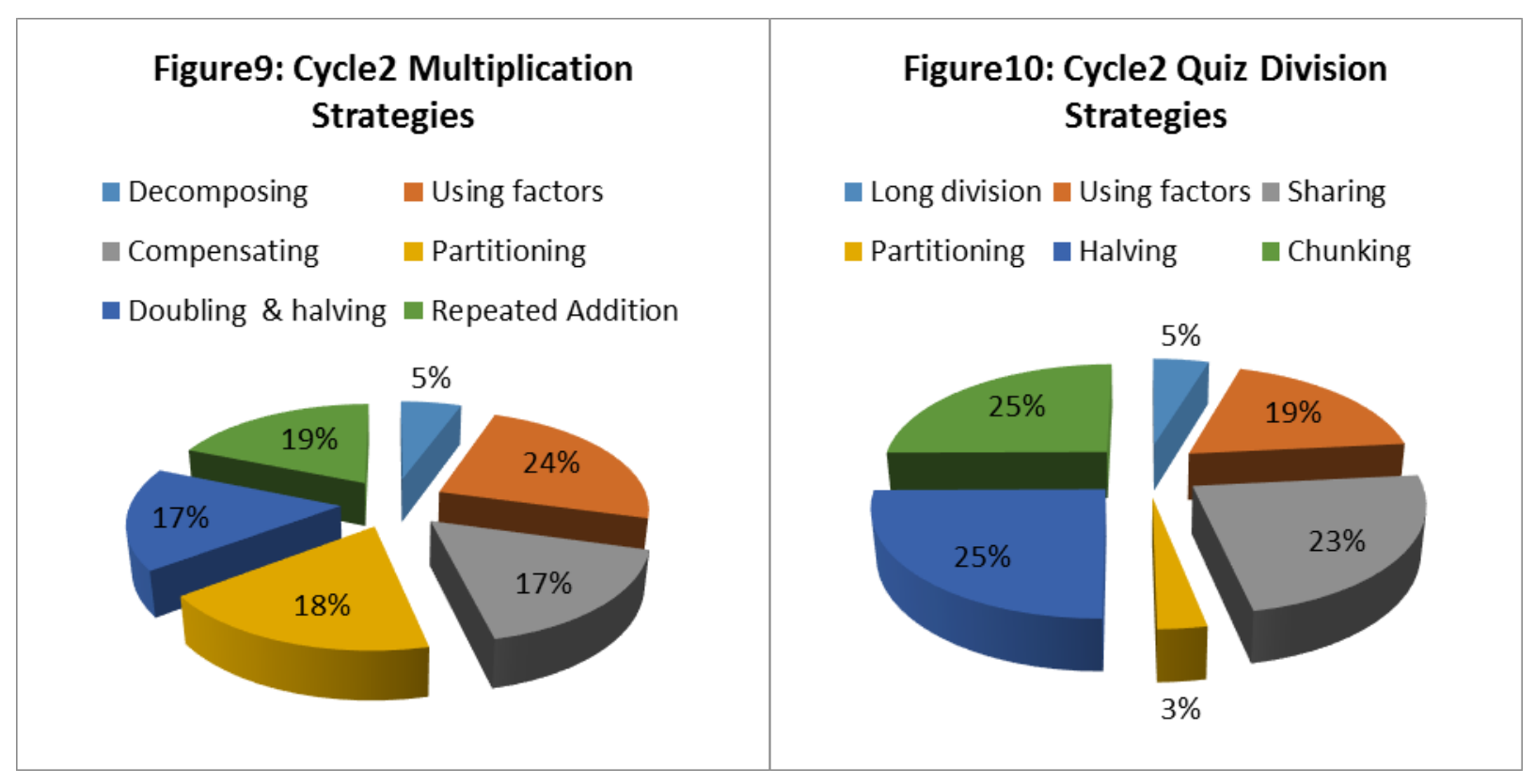

Students' adding and subtracting results had also improved. The percentages of students using regrouping was around $2 \%$ only (Figures 11\&12). 


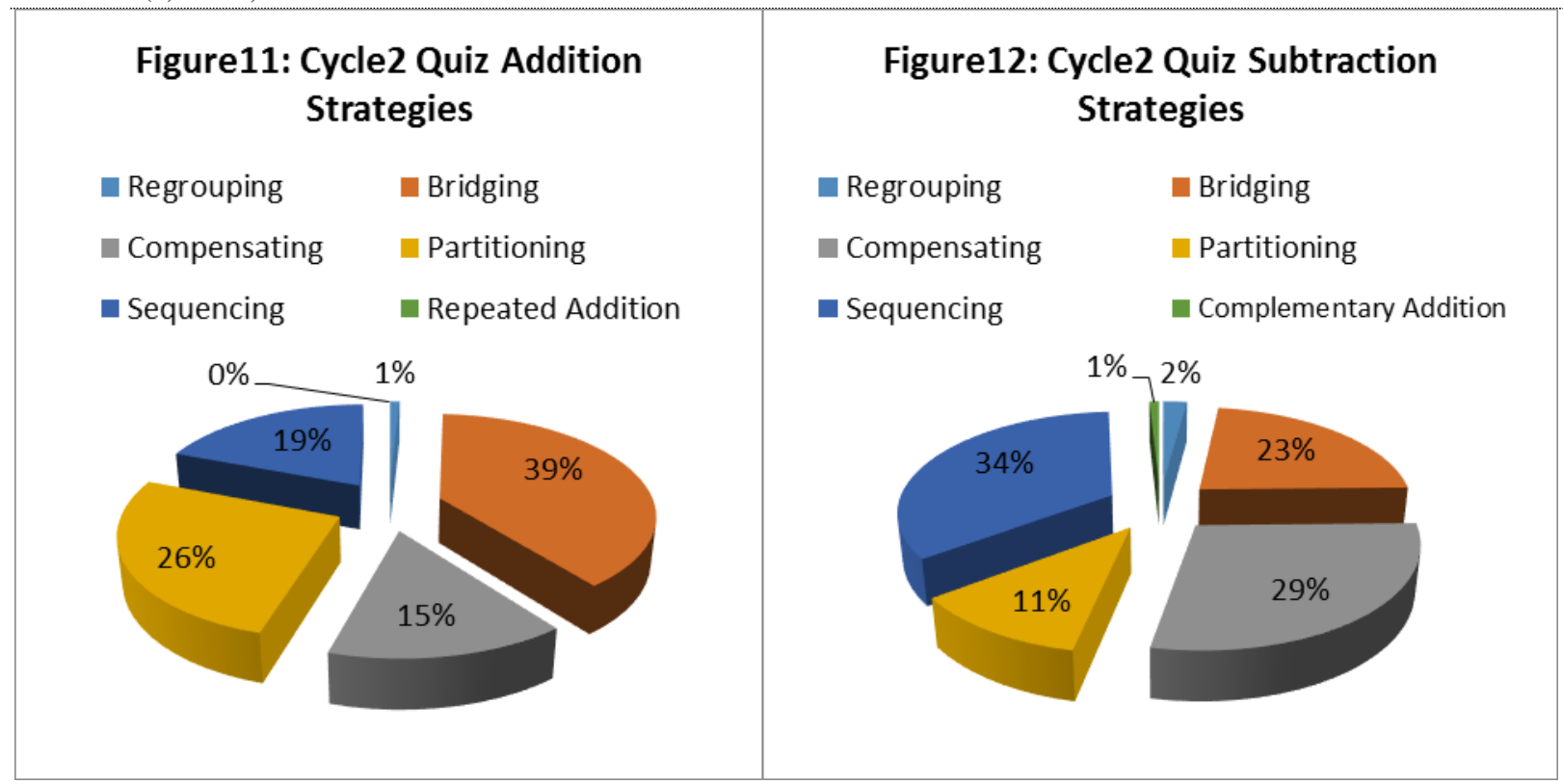

While analyzing students' results, many improvements on students' proficiency in relation to multiplication and division were found (Table 4\&5).

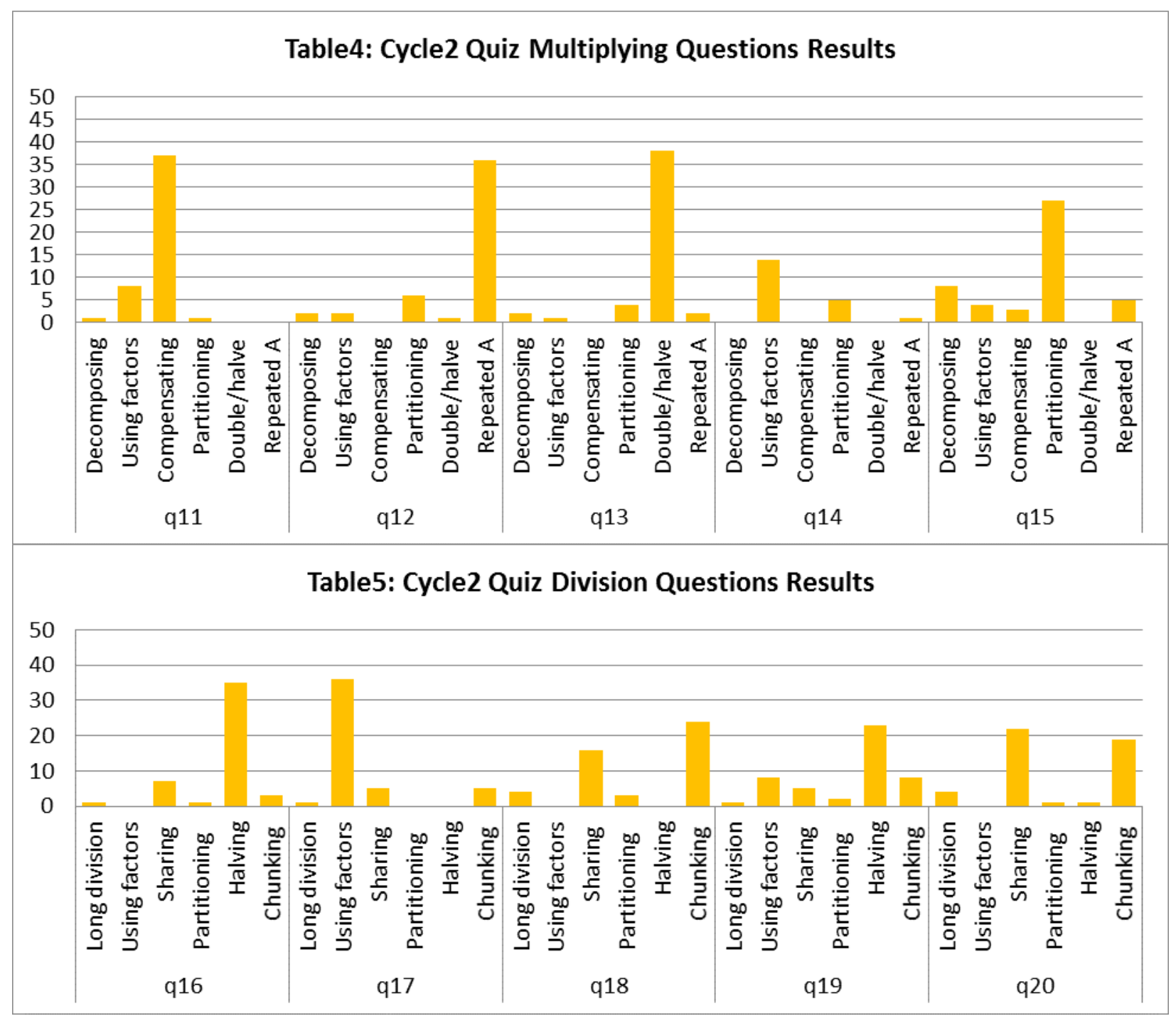

For example, 38 students solved Question $13(34 \times 5)$ by doubling $(34 \times 5 \rightarrow 34 \times 10=340 \div 2=170)$ which might be the best strategy to answer that question. Additionally, 36 students answered Question $17(96 \div 8)$ by factoring $(96 \div 2=48 \div 4=12)$ which might be the best strategy to solve it. Students did not use compensating for Questions 12, 13, and 14 because it 
was not a proper strategy for these questions. These results show clearly that students' proficiency improved a lot through this cycle.

After interviewing a few students after this cycle, interpretations about these changes were explained. Below are some of students' responses:

Participant 12: $\quad$ She used almost all the mental strategies with the four operations. She said, "I really benefited a lot from this practice; now I feel very confident while operating calculations. I think what we have practiced in these two months is easier than what we were practicing in our whole life. I have started to use these strategies mentally at my daily life."

Participant 5: He used bridging, compensating, and partitioning in adding and subtracting and only factoring and repeated addition in multiplying. This gives an indication that he needed more time to feel confident to use the mental strategies. He only used factoring in multiplying after a month of practicing multiplication, but he started using different addition and subtraction strategies after two months of practicing them. For division, he used halving, sharing, and chunking). He said, "I think all the strategies were easier than the methods we used to follow. The mental strategies for division are much easier than long division procedures."

Participant 38: She used only 2 strategies in each operation, and she was the only one who used regrouping in all the given operations. She said, "I believe these strategies are good, but two months of practicing were insufficient to overlearn them. I am not confident; I don't feel comfortable to try and make mistakes".

Having self-steam and being respected by peers is very important for students' performance development, as it is the fourth stage of the hierarchy of needs to achieve or master learning (McLeod, 2007). That is why; some students may hesitate to try a new method to avoid making mistakes (Loveridge and Taylor, 2005). In general, by comparing the results of the three quizzes, it is clear that the students improved in using all the mental strategies through the three quizzes (Tables 6-9). As it can be seen, students' frequency of use of the traditional methods decreases significantly through the cycles to reach its lowest frequency in Cycle2 quiz.

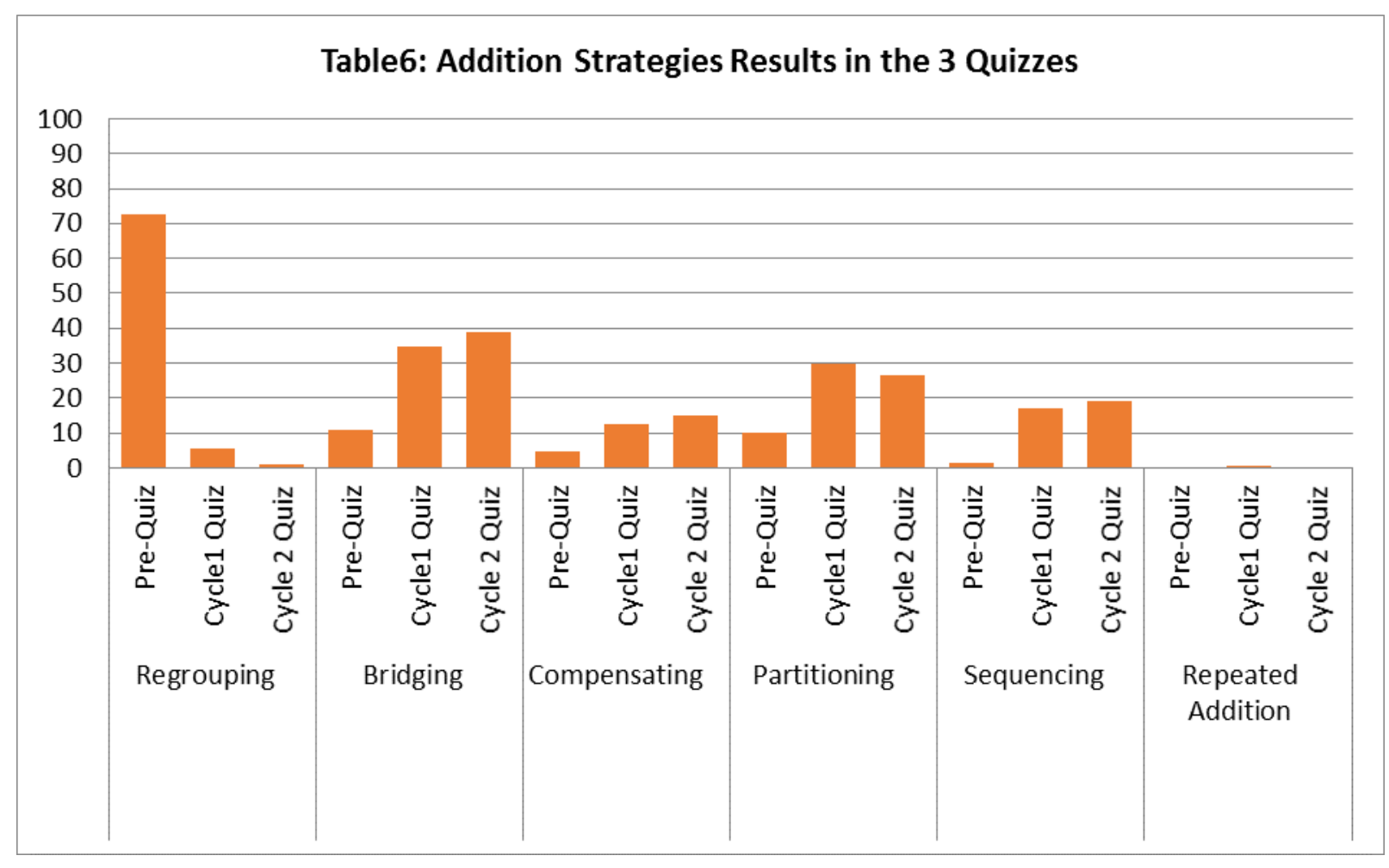



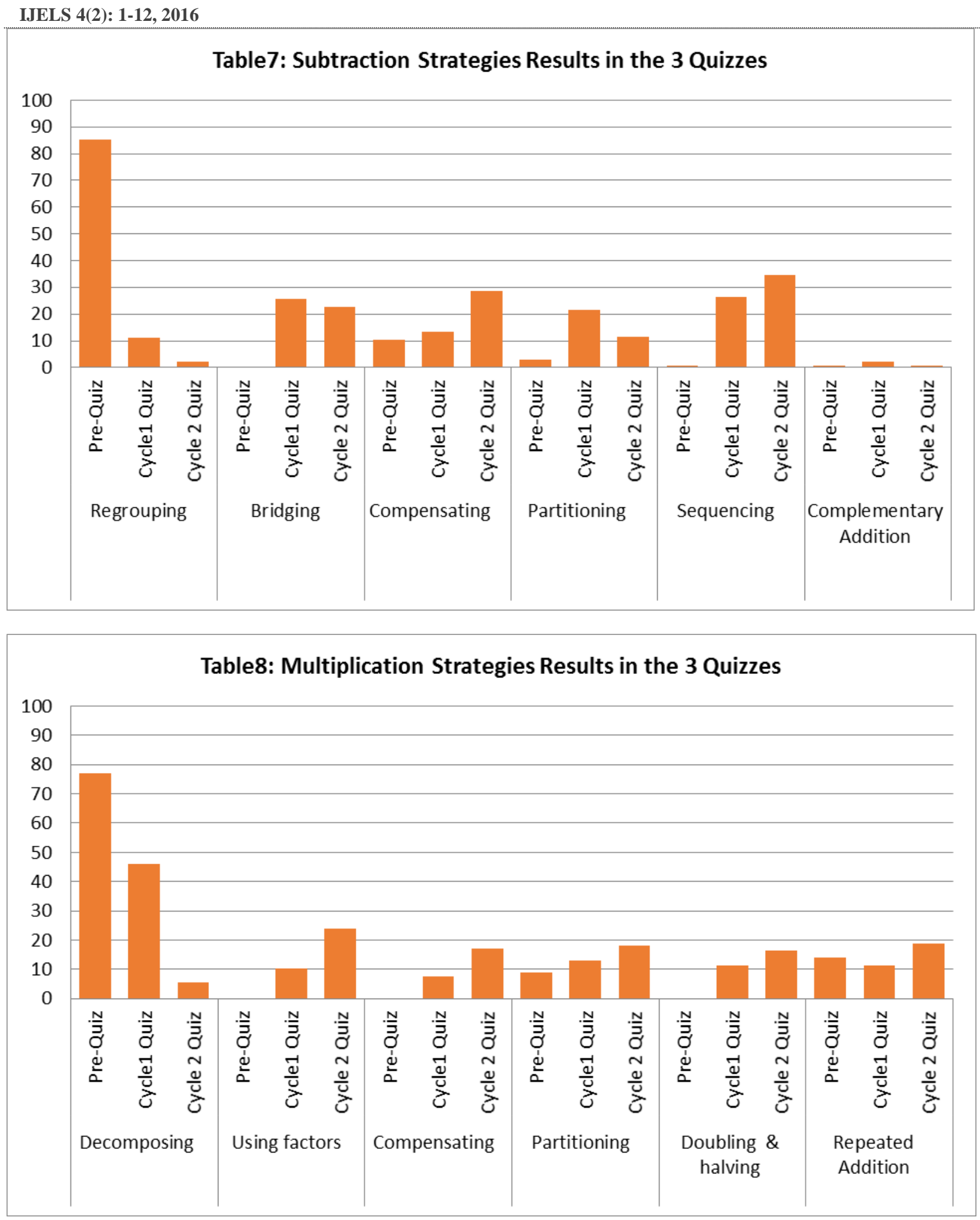


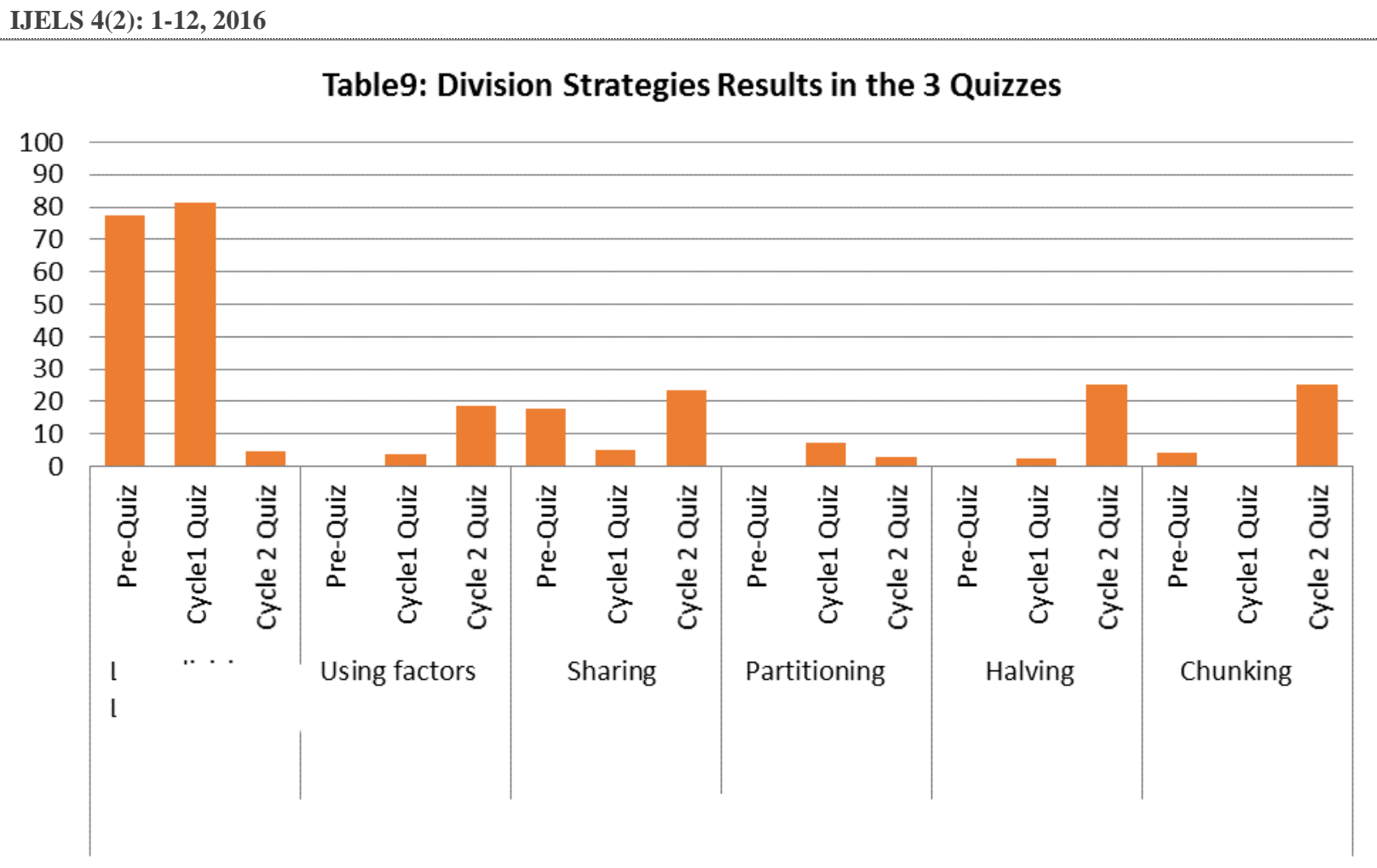

As it can be seen, students improved in adding and subtracting during the Cycle 2 quiz, which can prove that the more practice they experience, the more improvement they will show. This also was evident in a study by Mead and Maxwell (2010) who found similar improvement in an action research study when they provided counting-on strategy practice for their students over a period.

Finally, it was also investigated if there are any significant changes before and after the practice in solving the questions correctly. The test showed that there is no significant difference (Table 10).

Table 10: The Three Quizzes Success Results

\begin{tabular}{|c|c|c|c|c|}
\hline & $\mathrm{Q} \#$ & Pre-Quiz & $\begin{array}{c}\text { Cycle } 1 \\
\text { Quiz }\end{array}$ & $\begin{array}{c}\text { Cycle } 2 \\
\text { Qu iz }\end{array}$ \\
\hline \multirow{5}{*}{ Add ition } & 1 & 45 & 47 & 46 \\
\hline & 2 & 47 & 42 & 45 \\
\hline & 3 & 44 & 44 & 47 \\
\hline & 4 & 46 & 40 & 43 \\
\hline & 5 & 42 & 46 & 44 \\
\hline \multirow{5}{*}{ Subtraction } & 6 & 40 & 45 & 46 \\
\hline & 7 & 42 & 41 & 46 \\
\hline & 8 & 44 & 40 & 46 \\
\hline & 9 & 46 & 42 & 44 \\
\hline & 10 & 37 & 41 & 44 \\
\hline \multirow{5}{*}{ M u It ip lication } & 11 & 43 & 35 & 38 \\
\hline & 12 & 46 & 45 & 45 \\
\hline & 13 & 45 & 44 & 42 \\
\hline & 14 & 41 & 41 & 45 \\
\hline & 15 & 40 & 45 & 36 \\
\hline \multirow{5}{*}{ Division } & 16 & 38 & 42 & 41 \\
\hline & 17 & 40 & 42 & 41 \\
\hline & 18 & 40 & 42 & 43 \\
\hline & 19 & 38 & 37 & 42 \\
\hline & 20 & 35 & 42 & 42 \\
\hline
\end{tabular}

This last result was a 'success result', which might not prove anything in this study since it did not aim to study the success. Future studies with higher thinking questions can measure the success differences while using different mental strategies as other similar studies (Anghileri, 2006).

\section{Conclusion}

Gallagher and Ali (2007) mentioned that action research has two essential elements: to improve and to involve, and that was proven in this study. Involving the students in practical tasks was the best way to convince them about the efficiency of using the mental strategies. In a study, the low mental computation performance reported most likely 
reflected students' lack of opportunity to use the mental techniques they constructed based on their own mathematical knowledge (Reys et al., 1993, as cited in Rivera, 1996). Mental calculation strategies are not just knowledge that we can deliver to students; they are high level thinking applications which students need to practice to explore the relations among numbers. According to the cognitive learning theory, the ability of breaking down concepts to better understand them, and then combine them again to form a new whole is a high level thinking process of analysis, called synthesis in Bloom's taxonomy (University of Victoria, 2005, p. 2). This is exactly what the students' experienced when solving mathematic tasks using these mental strategies. The aim of this study was to let the students practice the mental strategies to improve their understanding of the relationship between numbers and therefore improve their proficiency in making calculations. This study showed the importance of providing practicing in the field of numeracy teaching to get effective results in a short period.

\section{Limitations}

There were a few limitations in this study; the first one was that it was conducted with the instructor's own students. Which means students might not have answered the questions honestly according to the strategies they thought were the best if they did not believe that the research had nothing to do with their grades. Also, they might not have been honest in answering the interview questions, because they could have been trying to impress their instructor. The second limitation was not using a quantitative measure for students' perspective about the mental strategies to compare it with their results; distributing a questionnaire to all students to compare their responses with their quiz results could have a significant impact on the study. The final limitation which could have affected the level of generalization of the study result was not using problem solving questions in the quizzes, which means the improvements in proficiency might not be very accurate since it excluded an important part of numeracy.

\section{References}

Anghileri, J. (2006). A study of the impact of reform on students' written calculation methods after five years' implementation of the National Numeracy Strategy in England, Oxford Review of Education, 32 (3), 363-380.

Biggs, J. and Tang, C. (2011). Teaching For Quality Learning at University. ${ }^{\text {th }}$ ed. Berkshire: Open University Press.

Brown, M. et al. (2003). The Key Role of Educational Research in the Development and Evaluation of the National Numeracy Strategy, British Educational Research Journal, 29(5), 655-672.

Craig, A. (2010). Comparing research into mental calculation strategies in mathematics education and psychology, Research in Mathematics Education, 12(1), 73-74.

Doabler, C. et al. (2012). Evaluating Three Elementary Mathematics Programs for Presence of Eight Research-Based Instructional Design Principles, Learning Disability Quarterly, 35 (4), 200-211.

Foxman, D. and Beishuizen, M. (2002). Mental calculation methods used by 11-year-olds in different attainment bands: a reanalysis of data from the 1987 apu survey in the UK, Educational Studies in Mathematics, 51,41-69.

Gallagher, K and Ali, K. (2007). Action Research and Initial Teacher Education in the UAE. 1st ed. UAE: HCT Press.

Heirdsfield, A. and Lamb, J. (2005). Mental Computation: The Benefits of Informed Teacher Instruction. Queensland University of Technology. Retrieved on 7 February 2015 from

http://www.merga.net.au/documents/RP452005.pdf

Jones, D. V. (2004). National numeracy initiatives in England and Wales: parallel attempts at achieving large-scale reform, Compare, 34 (4), 463-486.

Loveridge, J. Y. and Taylor, M. (2005). Children's views about mathematics learning after participation in a numeracy initiative, University of Waikato, Research in Education, 74, 83-90.

Maclellan, E. (2001). Mental Calculation: its place in the development of numeracy, Westminster Studies in Education, 24 (2), 145-154.

McLeod, S. (2007). Maslow's Hierarchy of Needs. Retrieved on 6 February 2015 from http://www.simplypsychology.org/maslow.html

Mead, K. and Maxwell, W.T. (2010). Using the counting on mathematics strategies: an action research case study, APMC, 15(3), 10-15.

Mertler, C. (2012). Action research Improving Schools and empowering Educators. $3^{\text {rd }}$ ed. California: SAGE Publications Ltd.

Murphy, C (2004). How do children come to use a taught mental calculation strategy? Educational Studies in Mathematics, 56, 3-18.

Piht, S. and Eisenschmidt, E. (2010). Mental Arithmetic Skills: Comparative Research Based on Estonian and Finnish Pupils, problems of education in the 21st century, 25, 99-108. 
Quirk, B. (2013). The Bogus Research in Kamii and Dominick's Harmful Effects of Algorithms Papers, Nonpartisan Education Review, 9(2), 1-3. Retrieved on 1 February 2015 fromhttp://www.wgquirk.com/kamii.htmlRace, P. (2010). Making Learning Happen: A guide for post-Compulsory education. 2nd ed. London: SAGE Publications Ltd.

Rivera, L. (1996). The Effect of Mental Computation Instruction on Third Grade Mathematic Student. Columbia University. Retrieved on 6 February 2015 from

http://ponce.inter.edu/cai/tesis/lmrivera/acknowled.htm

Thomson, I. (1999). Mental calculation strategies for addition and subtraction. Part 1. Mathematics in school, 28(5), 24. Thompson, I. (2000). Is The National Numeracy Strategy Evidence-Based? MT, 171, 23-27. Retrieved on 2 February 2015 from http://www.ianthompson.pi.dsl.pipex.com

Thompson, I. (2009). Mental Calculation, Mathematics Teaching, 213, 40-42.

Threlfall, J. (2002). Flexible mental calculation. Educational studies in Mathematics, 50, 29-47.

University of Victoria (2005), Bloom's Taxonomy of Educational Objectives and Verbs for the Objectives, pp. 1-14. Retrieved on 6 February 2015 from

http://www.atlantic.edu/program/academic/factgov/documents/BloomsTaxonomyinfo.pdf

\section{Appendix A: Interview Questions}

\section{The interviews questions were as follows:}

- Why did you use the specific mental approach in solving the question? Did you think it was easier or faster? Any other reasons?

- Which of the mental strategies do you believe now is easier than the vertical approach?

- Which approach do you think is not efficient and you would rather use the vertical method instead?

- Do you think practicing the numeracy mental strategies in class was effective in improving your confidence in using them?

- $\quad$ Do you think practicing the numeracy mental strategies in class was effective in improving your numeracy proficiency?

- Do you think practicing the numeracy mental strategies in class changed your perspective about using them?

- $\quad$ Did you start using the mental strategies in your daily life? Why?

- How could this learning experience change you to be a better math teacher? 